\title{
$24 \mathrm{kV}$ 급 배전반의 외함재질과 두께에 따른 Bus bar와 외함의 전자기 손실특성 분석
}

\section{Analysis on Electromagnetic Loss Characteristics of Bus bar and Enclosure according to the Specifications of Enclosures for a $24 \mathrm{kV}$ Switchgear}

\author{
허 정 일* 홍 종 기 ${ }^{*}$ 강 형 구 ${ }^{*}$ \\ (Jeong Il Heo · Jonggi Hong $\cdot$ Hyoungku Kang)
}

\begin{abstract}
This paper deals with the electromagnetic loss characteristics of enclosures for a $24 \mathrm{kV}$ high voltage switchgear by using a finite element method (FEM). A study on the electromagnetic characteristics of enclosures for a high voltage switchgear should be conducted to minimize the size and the temperature rising of a switchgear. Generally, the enclosures made by stainless steel are used to minimize the eddy current loss caused by the transporting current in Bus bars due to its non-magnetic characteristics although the price of stainless steel is expensive compared with other metal for enclosures. Therefore, a switchgear made by stainless steel enclosures could be fabricated as a small size and are applied to a switchgear in urban substations. On the contrary, the switchgear enclosures made by steel could be fabricated with relatively cheap manufacturing price. However, the temperature easily rises due to the transporting current in Bus bars because steel is a ferromagnetic material. Therefore, the size of a switchgear made by steel enclosures is relatively massive and installed in rural substations. In this paper, the electromagnetic losses in the enclosures of a switchgear according to various enclosure thicknesses are calculated and compared with each other. Especially, we proposed a hybrid type enclosures for a switchgear made by stainless steel (top and bottom enclosure) and steel (left and right enclosure). It is concluded that the cost electromagnetic performance of applying the hybrid type enclosure is favorable to develop a high voltage switchgear.
\end{abstract}

Key Words : Bus bar, Eddy current, Electromagnetic loss, FEM, Switchgear

\section{1. 서 론}

현대사회가 고도화함에 따라 전기의 사용량은 지속적으로 증가하고 있으며, 이에 따라 전력기기들도 대용량화로 되어 가는 추세이다. 또한, 송전계통의 고압화가 가속화 되고 있 는 실정이다. 송전계통과 배전계통을 통해 공급되는 전력은 배전반을 거쳐 여러 전력 수요부로 나누어 지고 있는데 이 러한 전력의 분배역할을 하는 것이 Bus bar이다. 전력기기 중 특히 배전반에서는 대전류 통전시 와류에 의한 영향 및 온도상승을 고려하는 것이 필수적이다. 대전류가 Bus bar를 통해 통전되면 배전반 내부 및 외함에서는 대전류로 인하여 줄손이 발생하여 발열 현상이 일어난다. 특히 도체에 흐르 는 전류가 시간적으로 변화한다면 발생한 자계에 의해 도체 에 인접한 주위 금속에 와전류가 흐르고, 줄손이 추가로 발 생하게 된다. 금속이 자성재료인 경우에는 자화에 의한 히 스테리시스 현상이 일어나며 히스테리시스손이 발생한다. 이러한 손실이 전력기기에 발생하면 기기의 수명 및 효율이

* 학생회원 : 한국교통대 첨단과학기술대 전기공학과 석사과정

† 교신저자, 정회원 : 한국교통대 첨단과학기술대 전기공학과 조교수

E-mail : kang@ut.ac.kr

접수일자 : 2012년 10월 31일

수정일자 : 2013년 6월 6일

최종완료 : 2013년 9월 10일
심각하게 저하되게 된다[1]. 그러므로 배전반 설계시에는 전 자기 손실을 고려한 설계가 이루어져야 하고 이와 동시에 경제성을 고려하여야 한다.

그러나 현재 이러한 연구가 많이 진행되지 않아 현장 경험 을 토대로한 설계가 이루어지고 있는 실정이며, 이 경우에 손 실과 경제성을 동시에 고려하지 않은 설계로 인하여 불필요 한 이격거리, 두께가 산출되어 경제적 낭비가 발생하고 있다.

본 논문에서는 $\mathrm{FEM}$ (Finite Elements Method)을 이용하 여 24[k $\mathrm{k}] / 2000[\mathrm{~A}]$ 급 MCSG(Metal Clad Switch Gear)의 모 선부와 차단부 사이를 연결하는 Bus bar와 외함부분을 배전 반의 상단에서 바라본 구조에 대하여 경제성과 전자기 손실 을 고려한 효율적인 설계안을 제시하고자 한다. 4 면이 $\mathrm{SS}$ (Stainless steel), St(Steel)인 재질의 외함과, Top • Bottom은 SS로 Left·Right는 St로 제작한 하이브리드형인 T/B SS, Top·Bottom은 St로 Left·Right는 SS로 제작한 하이브리드형인 $\mathrm{T} / \mathrm{B} \mathrm{St}$ 총 4 가지 조건에 대하여 비교 분 석하였다.

\section{Bus bar와 외함 해석모델 선정 및 전계해석}

\section{1 외함재질과 상간이격거리 선정}

그림 1 과 같이 상간 이격거리, 상과 외함과의 이격거리는 국내 중전기 업체의 $24[\mathrm{kV}] / 2,000[\mathrm{~A}]$ 급 제품을 참고하여 모 
표 1 외함의 사양

Table 1 Specification of enclosure

\begin{tabular}{|c|c|c|}
\hline \multirow{2}{*}{ 외함타입 분 } & $\begin{array}{c}\text { 너비 }[\mathrm{mm}] \times \\
\text { 두께 }[\mathrm{mm}]\end{array}$ & 면적 $\left[\mathrm{mm}^{2}\right]$ \\
\hline \multirow{3}{*}{ Top, Bottom } & $1002 \times 1$ & 1002 \\
\cline { 2 - 3 } & $1004 \times 2$ & 2008 \\
\cline { 2 - 4 } & $1006 \times 3$ & 3018 \\
\cline { 2 - 4 } & $1008 \times 4$ & 4032 \\
\hline \multirow{2}{*}{ 괴하맘타입 } & $\begin{array}{c}\text { 높이 }[\mathrm{mm}] \times \\
\text { 두께 }[\mathrm{mm}]\end{array}$ & 면적 $\left[\mathrm{mm}^{2}\right]$ \\
\hline \multirow{2}{*}{ Left, Right } & $514 \times 1$ & 514 \\
\cline { 2 - 4 } & $514 \times 2$ & 1028 \\
\cline { 2 - 3 } & $514 \times 3$ & 1542 \\
\cline { 2 - 3 } & $514 \times 4$ & 2056 \\
\hline
\end{tabular}

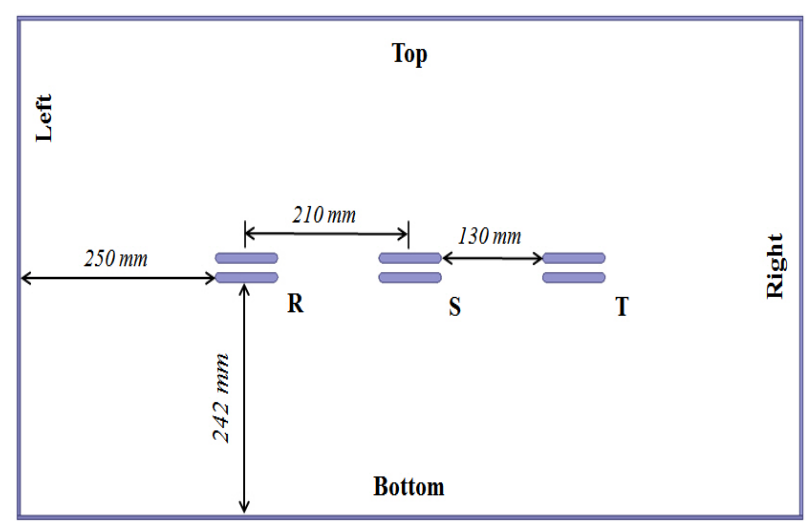

그림 1 외함과 버스바의 단면도

Fig. 1 Cross sectional view of enclosure and Bus bar model

델링 하였다. 해석을 수행하기 위해서 배전반 외함의 재료 로 많이 쓰이고 있는 비자성체인 $\mathrm{SS}$, 자성체 $\mathrm{St}$, 하이브리 드 타입으로 $\mathrm{T} / \mathrm{B} \mathrm{SS}, \mathrm{T} / \mathrm{B}$ St를 선정하였다. Bus bar의 재 질로는 기존 배전반에서 많이 사용되는 copper로 선정하였 다. 표 1 은 외함의 두께별 치수와 면적을 나타내었다. 외함 의 두께를 $1[\mathrm{~mm}], 2[\mathrm{~mm}], 3[\mathrm{~mm}], 4[\mathrm{~mm}]$ 로 선정한 이유는 외함의 두께가 증가할수록 손실특성과 제조원가에 대한 추 이를 확인하기 위함이다. 외함의 재질과 두께에 따른 전자 기 특성을 알아보기 위해서 Bus bar의 크기는 기존의 24 $[\mathrm{kV}] / 2000[A]$ 급 전류 통전용으로 많이 사용되는 너비와 두께 가 $80[\mathrm{~mm}] \times 10[\mathrm{~mm}]$ 인 Bus bar를 선정하였다. 또한 Skin effect로 인하여 전류가 도체의 표면에 집중되어 흐르기 때 문에 효율성을 고려하여 2병렬 구조를 택하였다.

\section{2 전계해석조건 및 결과}

선정된 모델에 대하여 손실해석에 앞서 Bus bar와 외함 간의 전기적 안정도를 확인하기 위해서 전계해석을 수행하 였다. 고압배전반의 전계해석을 위하여 정격전압 $24[\mathrm{kV}]$ 에 대한 $\mathrm{IEC}$ 의 뇌임펄스 절연파괴 시험규정을 준수하여 125 $[k V]$ 의 전압전원을 인가하였다. 실제로 고압배전반의 절연시
험에서 $\mathrm{R}$ 상에 대한 시험은 $\mathrm{S}$ 상과 $\mathrm{T}$ 상 그리고 외함을 접지 한다. S상에 대한 시험은 해석결과는 $\mathrm{R}$ 상과 큰 차이를 보이 지 않아 $\mathrm{R}$ 상에 대한 시험을 준수하여 전계해석을 수행하였 다.

일반적으로 기체절연매질의 절연내력특성은 전극시스템에서 최대전계 $\left(E_{M A X}\right)$ 크기에 의해서 결정된다고 알려져 있다[2]. 그 중 준 평등 조건에서의 기중 절연파괴 기준전계는 3.5 $[\mathrm{kV} / \mathrm{mm}] \sim 4.5[\mathrm{kV} / \mathrm{mm}]$ 로 알려져 있다[3]. 기준전계가 의미 하는 것은 공기를 절연매질로 하는 전력기기를 설계할 때 기기의 최대전계가 기준전계를 초과하면 절연적으로 불안정 하여 절연파괴가 일어날 확률이 높다는 것을 의미한다. 즉, 기준전계 이하로 설계되어야 절연적으로 안정하다고 할 수 있다.

그림 1 과 표 1 의 규격에 대해서 전계해석을 수행한 결과 모든 타입에서 최대전계가 $4.5[\mathrm{kV} / \mathrm{mm}]$ 를 초과하지 않는 것 으로 나타났다. 즉, 절연적으로 안정적인 조건인 것으로 판 단된다.

\section{3. 전자기 손실 해석}

\section{1 손실의 원인 및 영향}

전력기기 설계 시 절연적으로 안정성을 고려해야 하는 것 과 마찬가지로 전자기 손실 또한 고려해야 한다. 전자기 손 실은 결과적으로 열손실로 이어져 배전반 내부의 온도를 높 이게 되고 기준온도 이상으로 상승하게 되면 기기의 소손이 나 외함혼촉 시 화상과 같은 인명피해를 유발할 가능성이 있다. 대전류 전력기기에서의 온도상승은 크게 전자기 손실 로 인한 온도상승 및 주변온도 상승으로 인한 요인이 대부 분이고 배전반의 경우 구성조건이나 작동조건이 광범위하기 때문에 과도한 온도상승의 원인은 다양한데 대표적으로 과 도한 외부온도 상승, 적정설치용량 초과, 단락 또는 과부하, 부적절한 부품 및 배전반 내 위치배분 등이 있다[1]. 이와 같은 원인들 중 Bus bar에 흐르는 전류로 인한 자계에 의해 서 발생한 와류에 의해 열이 발생하는데, 이 와류는 외함재 질의 영향을 받는다. 따라서 비자성체인 $\mathrm{SS}$ 과 자성체인 $\mathrm{St}$ 의 특성에 따른 와류에 의한 손실과 원자재 가격을 고려한 조합을 통하여 손실특성 향상과 원자재 가격을 낮추기 위한 방안으로 $2 \mathrm{D} \mathrm{FEM을} \mathrm{통하여} \mathrm{해석을} \mathrm{수행하였다.} \mathrm{경계조건}$ 은 Neumann에서 수행하였다.

\section{2 자속밀도의 영향}

도체에 전류가 통전되면 자기장이 형성되어 주변 도체에 전자기 손실이 발생되고 금속의 재질에 따라서 다르게 나타 난다. SS는 비자성체로 자기장을 투과시켜 와류에 대한 영 향이 적고, 히스테리시스손이 발생하지 않는 특성이 있다. 반면에 St는 강자성체로 자기장에 그대로 자화되는 특성을 보이고 와류손과 히스테리시스손이 발생한다. 본 연구에서 는 SS, St, T/B SS, T/B St의 구조에 대해 손실과 제조원 가 절감을 위해 자속밀도분포 분석을 하였다.

그림 2는 4 면이 SS로 구성된 외함의 자속밀도분포를 나 타내었다. 비자성체인 SS는 그림과 같이 자기장을 투과시키 


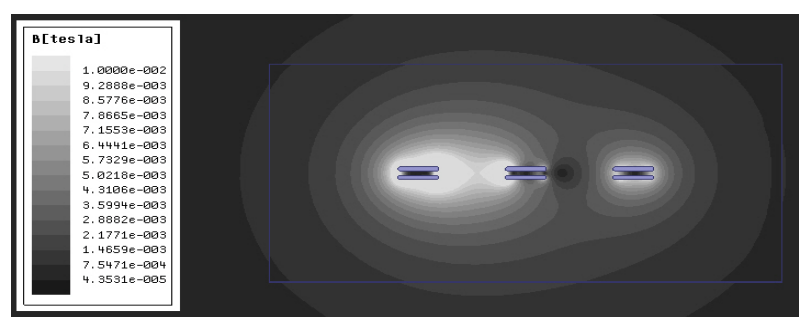

그림 $2 \mathrm{SS}$ 의 자속밀도분포 (Phase : $0 \mathrm{deg}$ )

Fig. 2 Magnetic flux density distribution of SS (Phase : 0 deg)

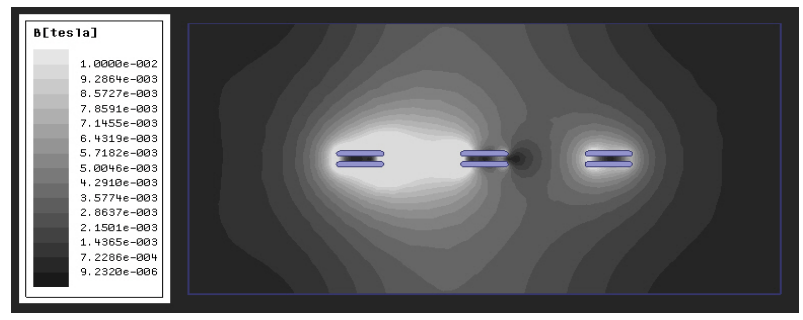

그림 3 St의 자속밀도분포 (Phase : $0 \mathrm{deg}$ )

Fig. 3 Magnetic flux density distribution of St (Phase : 0 deg)

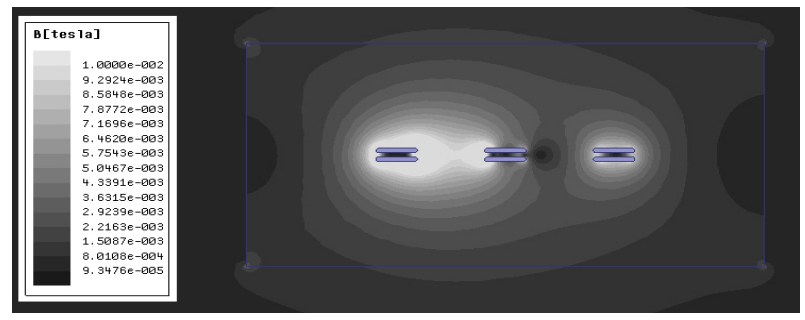

그림 4 T/B SS의 자속밀도분포 (Phase : $0 \mathrm{deg}$ )

Fig. 4 Magnetic flux density distribution of T/B SS (Phase 0 deg)

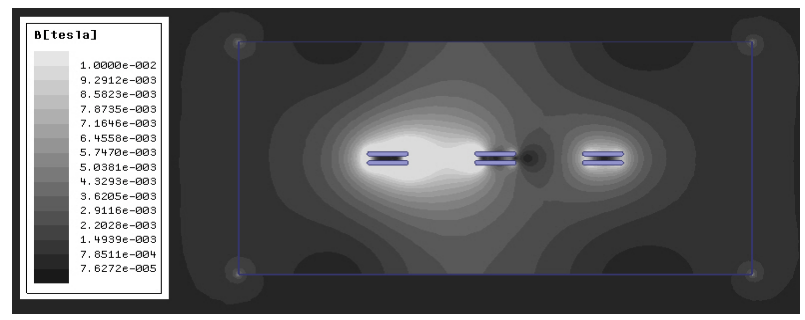

그림 $5 \mathrm{~T} / \mathrm{B}$ St의 자속밀도분포 (Phase : $0 \mathrm{deg}$ )

Fig. 5 Magnetic flux density distribution of T/B St (Phase : 0 deg)

는 것으로 보여진다. 그림 3 은 4 면이 St로 구성된 외함의 자 속밀도분포에 대해서 나타내었다. 강자성체인 St는 그림과 같 이 자기장을 투과시키지 않고 자화시키는 것으로 나타난다.

그림 4 와 그림 5 는 각각 손실과 원재료 절감을 고려한 T/B SS, T/B St 구조의 자속밀도분포를 나타내었다. 이 구 조는 고가의 비자성체 $\mathrm{SS}$ 과 저가의 강자성체인 $\mathrm{St}$ 를 조합 하여 효율적인 설계를 도출하기 위함이다. 이 구조의 자속
밀도분포는 비자성체인 SS부분은 자속을 투과시키고 강자 성체인 $\mathrm{St}$ 부분에서는 자속에 의해 자화되고 있는 것을 확인 할 수 있다. 이와 같은 비자성체와 자성체의 특성 때문에 외함에 발생되는 손실값이 다르게 나타난다.

\section{3 정자계 지배방정식}

Bus bar에 교류전류가 흐를 때 준정상 맥스웰 방정식은 다음과 같다.

$$
\begin{aligned}
& \nabla \times \vec{H}=\vec{J} \\
& \nabla \times \vec{E}=-\frac{\partial \vec{B}}{\partial t} \\
& \nabla \cdot \vec{B}=0
\end{aligned}
$$

식(3)으로부터 자속밀도 $\vec{B}$ 는 자기 벡터 포텐셜 $\vec{A}$ 를 이용 하여 다음과 같이 표현할 수 있다.

$$
\vec{B}=\nabla \times \vec{A}=\mu \vec{H}
$$

식(1)으로부터 지배방정식을 다음과 같이 다음과 같이 표 현할 수 있다.

$$
\nabla \times \frac{1}{\mu}(\nabla \times \vec{A})=\vec{J}=\overrightarrow{J_{s}}+\overrightarrow{J_{e}}
$$

여기서, $\overrightarrow{J_{s}}$ 는 전원전류이고, $\overrightarrow{J_{e}}$ 는 와전류이다. 도체에 유기되는 와전류는 다음과 같고,

$$
\vec{J}=\sigma_{e} \vec{E}=-\sigma_{e} \frac{\partial \vec{A}}{\partial t}
$$

이로부터 지배방정식은 다음과 같이 다시 표현할 수 있 다.

$$
\nabla \times \frac{1}{\mu}(\nabla \times \vec{A})=\overrightarrow{J_{s}}-\sigma_{e} \frac{\partial \vec{A}}{\partial t}
$$

\section{4 전자기 손실 해석 및 분석과 제조원가 비교}

본 논문에서는 표 1 의 Bus bar와 외함의 사양을 토대로 전자기 손실을 해석하였다. 그림 6 부터 그림 9 까지 각각 타입 별로 외함의 좌측 상단부분의 전자기 손실 분포를 나타냈다.

그림 10 의 그래프와 같이 전자기 손실은 외함의 두께에 반비례하고, 강자성체인 St로 제작된 외함의 경우에는 $\mathrm{SS}$ 에 비해 손실이 큰 것을 알 수 있다. 각 타입별 두께증가에 대 한 손실의 차이를 분석해보면 외함의 두께가 $1[\mathrm{~mm}]$ 일 경우 $\mathrm{SS}$ 의 경우가 가장 손실이 적었으며, 나머지 타입별 손실은 SS대비 St 293[\%], T/B SS 129[\%], T/B St 153[\%]의 값을 나타냈다.

$2[\mathrm{~mm}]$ 일 경우 역시 $\mathrm{SS}$ 의 경우가 가장 손실이 적었으며 나머지 타입별 손실은 SS대비 St 217[\%], T/B SS 103[\%], 


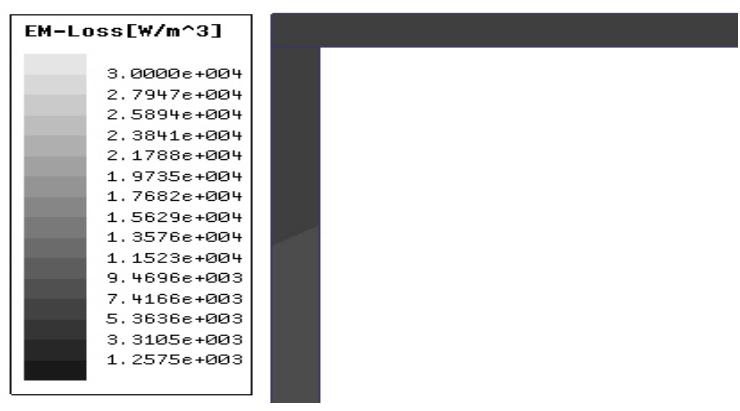

그림 $6 \mathrm{SS}$ 의 전자기 손실 분포 (두께 : 4[mm])

Fig. 6 Electromagnetic loss distribution of SS (Thickness : $4[\mathrm{~mm}])$

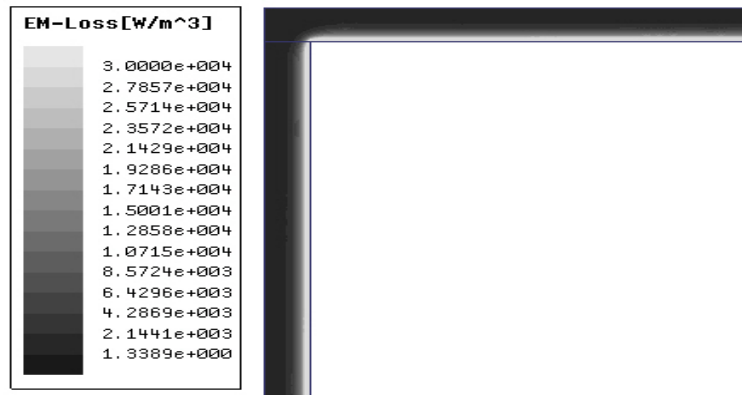

그림 $7 \mathrm{St}$ 의 전자기 손실 분포 (두께 : $4[\mathrm{~mm}]$ )

Fig. 7 Electromagnetic loss distribution of St (Thickness : $4[\mathrm{~mm}]$ )

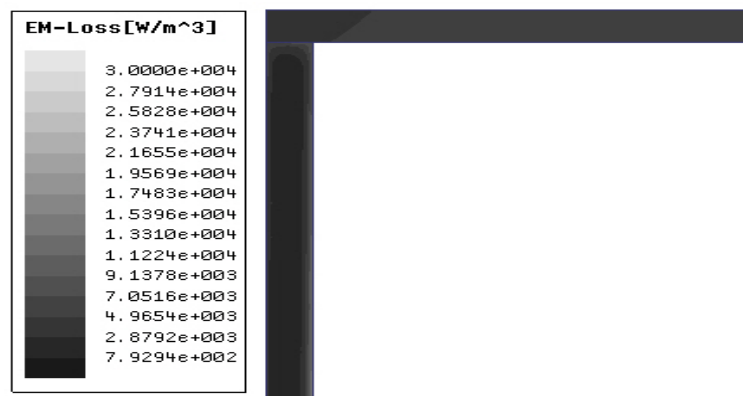

그림 $8 \mathrm{~T} / \mathrm{B} \mathrm{SS}$ 의 전자기 손실 분포 (두께 : $4[\mathrm{~mm}]$ )

Fig. 8 Electromagnetic loss distribution of $\mathrm{T} / \mathrm{B}$ SS (Thickness : $4[\mathrm{~mm}]$ )

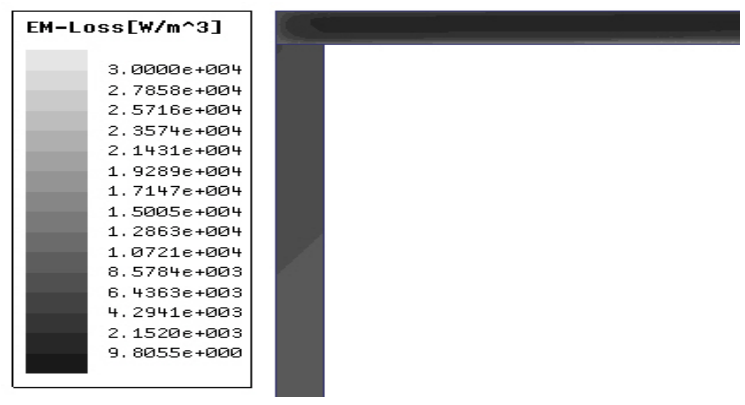

그림 $9 \mathrm{~T} / \mathrm{B} \mathrm{St}$ 의 전자기 손실 분포 (두께 : $4[\mathrm{~mm}]$ )

Fig. 9 Electromagnetic loss distribution of $\mathrm{T} / \mathrm{B} \mathrm{St}$ (Thickness : $4[\mathrm{~mm}]$ )

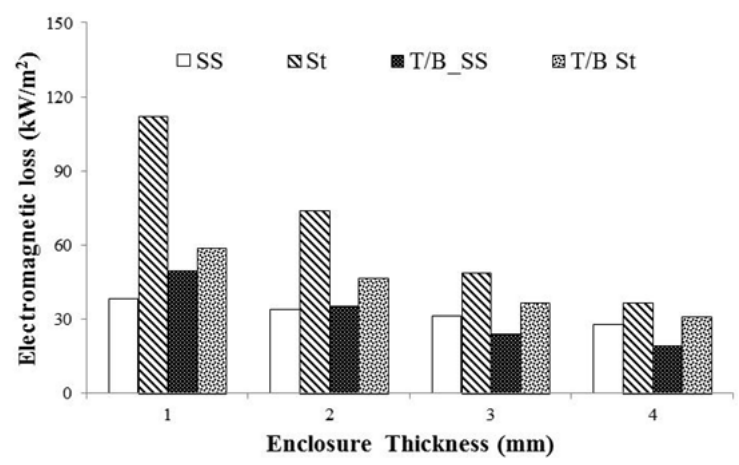

그림 10 외함재질과 두께에 따른 외함의 전자기 손실

Fig. 10 Enclosure electromagnetic loss according to enclosure materials and thickness

표 2 외함의 제조원가

Table 2 manufacturing cost of enclosure

단위 : 원

\begin{tabular}{|c|c|c|c|c|}
\hline 구분 & $1[\mathrm{~mm}]$ & $2[\mathrm{~mm}]$ & $3[\mathrm{~mm}]$ & $4[\mathrm{~mm}]$ \\
\hline $\mathrm{SS}$ & 9,738 & 19,501 & 29,290 & 39,105 \\
\hline $\mathrm{St}$ & 2,823 & 5,654 & 8,492 & 11,337 \\
\hline $\mathrm{T} / \mathrm{B} \mathrm{SS}$ & 7,393 & 14,812 & 22,257 & 29,727 \\
\hline $\mathrm{T} / \mathrm{B} \mathrm{St}$ & 5,167 & 10,342 & 15,525 & 20,715 \\
\hline
\end{tabular}

$\mathrm{T} / \mathrm{B}$ St $136[\%]$ 의 값을 나타났다. $3[\mathrm{~mm}]$ 일 경우에는 $\mathrm{T} / \mathrm{B}$ $\mathrm{SS}$ 가 가장 손실이 적었으며, $\mathrm{SS}$ 대비 나머지 타입별 손실은 St 157[\%], T/B SS 77[\%], T/B St 116[\%]로 나타났다. 4 $[\mathrm{mm}]$ 일 경우에도 $\mathrm{T} / \mathrm{B} \mathrm{SS}$ 가 가장 손실이 적었으며, $\mathrm{SS}$ 대비 나머지 타입별 손실은 St 130[\%], T/B SS 68[\%], T/B St $111[\%]$ 로 나타났다. 결과적으로 두께가 $1[\mathrm{~mm}]$ 에서 $4[\mathrm{~mm}]$ 까 지 증가할 때 손실은 각각 $\mathrm{SS}$ 는 27[\%], St는 68[\%], T/B SS 62[\%], T/B St 46[\%]가 감소하였다.

표 2 는 경제적인 외함제작을 위하여 제조단가를 가정하여 계산해 보았다. 표 1 에 나타난 규격에서 높이를 $100[\mathrm{~mm}]$ 로 가 정하여 한국물가정보에서 공시한 2012년 10월 물가를 반영하 여 계산하였다[4]. 두께 $4[\mathrm{~mm}]$ 의 경우에 가장가격이 비싼 $\mathrm{SS}$ 대비 St 29[\%], T/B SS 76[\%], T/B St 53[\%]의 수준이었다.

결과적으로 $\mathrm{SS}$ 는 두께증가에 따른 손실감소는 효과가 적 은 것으로 판단된다. 즉 배전반 설계시에 $\mathrm{SS}$ 는 옥내와 같이 공간적인 제약이 많은 곳에는 적합할 것으로 예상되며, 두께 에 대한 영향이 적으므로 두께를 증가시켜 설계하는 것은 제조원가 상승대비 비효율적인 것으로 판단된다. St는 손실 특성은 나쁘지만 가격적인 측면에서 활용도가 높아 옥외 설 치 배전반에서 외함의 부피를 증가시키면 손실특성이 나아 질 것으로 판단된다. 특히 $\mathrm{T} / \mathrm{B} \mathrm{SS}$ 는 외함의 두께가 $3[\mathrm{~mm}]$ 이상 부터는 $\mathrm{SS}$ 보다 손실이 더 적게 나타났다. 즉 $\mathrm{FEM}$ 해석 만을 놓고 보았을 때 손실특성이 좋지만 고가인 SS와 손실 특성은 나쁘지만 저가인 St의 혼합한 하이브리드 형식의 외 함의 제작이 가장 효율적인 것으로 보여지며, 이와 같은 결 과는 앞으로 실증실험을 통해 검증이 필요하다고 판단된다. 


\section{4. 결 론}

본 논문에서는 배전반 외함의 재질과 두께에 따른 외함의 손실에 대해서 $\mathrm{FEM}$ 을 통해 분석하였다. 고가인 비자성체 $\mathrm{SS}$ 과 저가인 자성체 St를 이용하여 손실과 외함 제조단가 측면에서 고려하였다. 기존의 배전반의 외함재질로 사용되 어온 $\mathrm{SS}, \mathrm{St}$ 과 본 논문에서 제시한 $\mathrm{T} / \mathrm{B} \mathrm{SS}, \mathrm{T} / \mathrm{B} \mathrm{St}$ 과 같 은 하이브리드형 타입을 선정하였고 손실과 제조원가에 대 하여 비교 분석 하였다.

$\mathrm{SS}$ 는 두께가 증가함에 따라서의 손실이 27[\%] 감소하였 고, 두께 증가에 따른 영향은 크게 나타나지 않는 것으로 보 여진다. 즉, $\mathrm{SS}$ 는 좋은 손실특성을 이용해 작은 부피와 높 은 손실특성이 요구되는 옥내 배전반 제작에 적합하고, St는 손실이 두께에 따라서 68[\%] 감소되는 특성을 보이고 제조 원가가 상대적으로 저렴하기 때문에 옥외에 설치되는 배전 반 제작에 적합할 것으로 판단된다.

$\mathrm{T} / \mathrm{B} \mathrm{SS}$ 과 $\mathrm{T} / \mathrm{B}$ St은 손실과 가격을 고려하여 효율적인 설계를 도출하기 위해 연구를 수행하였다. 그 결과 일정 두 께 이상에서 $\mathrm{T} / \mathrm{B}$ SS인 경우의 손실이 SS보다 손실이 더 적은 것을 확인하였고 제조단가 또한 더 저가인 것으로 나 타났다.

향후 해석결과의 신뢰성을 향상시키기 위해서 온도상승 실험을 수행하고, 실험을 통해 얻은 결과를 이용한 온도해석 을 수행할 계획이다. 이와 같은 연구결과는 경제성을 고려 한 고압배전반 설계법 개발에 도움이 될 것으로 판단된다.

\section{참 고 문 헌}

[1] 이방욱, 강종성, 손종만, 최원준, 서정민, "대전류 통전 시 배전반내의 열적 현상에 관한 연구”, 대한전기학회 추계학술대회 논문집, pp. 1051-1053, 1999.

[2] Y. Nishikori, S. Kojima, and T. Kouno, Electrical Engineering in Japan, vol. 139, no. 26, 2002.

[3] 남석호, 강형구, “고전압 전력기기 개발을 위한 기중 절 연파괴특성 분석에 관한 연구”, KIEE Tran., vol. 60, no.5, pp.1005-1010, 2011.

[4] “한국물가정보”, 2012. 10.

[5] 김중경, 한성진, "해석적 기법을 이용한 초고압 GIS용 삼상모선의 온도분포 해석”, KIEE Trans., vol. 55B, no. 4, pp. 196-201, 2006.
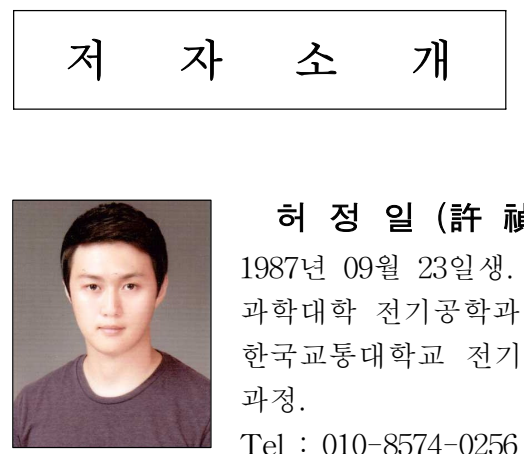

\section{허 정 일 (許 禎 日)}

1987년 09월 23일생. 2012년 충주대 첨단 과학대학 전기공학과 졸업. 2012년 현재 한국교통대학교 전기공학과 대학원 석사 과정.

Tel : 010-8574-0256

E-mail : jiheo@ut.ac.kr

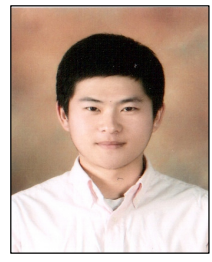

\section{홍 종 기 (洪 鐘 基)}

1987년 10월 13일생. 2012년 충주대 첨단 과학대학 전기공학과 졸업. 2012년 현재 한국교통대학교 전기공학과 대학원 석사 과정.

Tel : 010-7158-6889

E-mail : hjg@ut.ac.kr

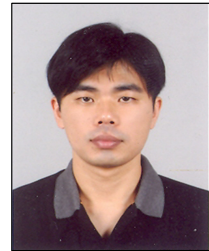

\section{강 형 구 (姜 亨 求)}

1973년 08월 04일생. 1997년 성균관대 공 과대 전기공학과 졸업. 1999년 도 대학원 전기공학과 졸업 (공학석사). 2005년 연 세대 대학원 전기·전자공학과 졸업 (공학 박사). 2005 2009년 현대중공업 선임연 구원, 2009 현재 한국교통대학교 전기공 학과 부교수.

Tel : 043-841-5145

Fax : 043-841-5140

E-mail : kang@ut.ac.kr 